\title{
Systematic Review and Meta-Analysis of
} Bearing Dislocation in Lateral Meniscal Bearing Unicompartmental Knee Replacement: Domed versus flat tibial surface.

AUTHORS:

Ms. Irene Yang1, Mr. Thomas W. Hamilton ${ }^{1 \& 2}$, Dr. Stephen J. Mellon', Professor David W Murray ${ }^{1 \& 2}$.

${ }^{1}$ Nuffield Department of Orthopaedics, Rheumatology and Musculoskeletal Sciences, University of Oxford, UK

2 Nuffield Orthopaedic Centre, Oxford, UK

Correspondence; Irene Yang, irene.yang@ndorms.ox.ac.uk.

Author Contributions Statement:

All authors have made substantial contributions to either; research design, acquisition, analysis and interpretation of data; or drafting of the paper and revising it critically.

All authors have read and approved the final submitted manuscript. 
Page 2 of 33

\section{Abstract}

Background: Bearing dislocation is a problem following mobile bearing Oxford lateral Unicompartmental Knee Replacement (UKR). Therefore the design of the tibial component was changed from flat to domed with a biconcave bearing to increase entrapment. This systematic review compared the dislocation and revision rates of the two designs.

Methods: Two authors independently searched MEDLINE, EMBASE and ISI Web of Science reference lists of retrieved articles, and the internet. Randomised, cohort, case-control and case studies of adult patients with lateral knee osteoarthritis treated with flat or domed Oxford lateral UKR and their outcomes were included. The overall dislocation rate and the annual revision rate (per 100 component years) were determined.

Results: Nine studies (937 knees) met the inclusion criteria (3 flat, 6 domed). Four studies (all domed) had a low risk of bias and five had a high risk ( 3 flat, 2 domed), so data should be interpreted with caution. The bearing dislocation rate decreased from $17 \%$ (flat) to $3.7 \%$ (domed). Dislocations occurred on average at 16 months and medial dislocations were most common. The revision rate excluding dislocation decreased from 1.1\%pa to 0.7\%pa. PROSPERO registration: CRD42019139250.

Conclusion: Modifying the tibial component from a flat to a domed shape decreased in the bearing dislocation rate to $3.7 \%$ and increased the 10 year survival rate excluding dislocation to $93 \%$. The dislocation rate is still relatively high so bearing stability should be assessed intra-operatively and if unacceptable a fixed bearing version of the Oxford lateral tibial component can be inserted. 
Page 3 of 33

KEYWORDS (5): Knee Replacement; Lateral; Implant survival; Bearing dislocation; Implant design. 
Page 4 of 33

\section{Abbreviations}

- UKR: Unicompartmental Knee Replacement

- ODL: Oxford Domed Lateral

- TKR: Total Knee Replacement

- PE: Polyethylene

- RCTs: Randomised Control Trials

- PTIR: Patient Time Incidence Revision Rate

- Cl: Confidence Interval

- MINORS: Methodological Index for evaluation of Non-Randomized Studies

- ACL: Anterior Cruciate Ligament

- LCL: Lateral Collateral Ligament

- NJR: National Joint Registry

- UKA: Unicompartmental Knee Arthroplasty

- UCA: Unicondylar Arthroplasty

- UCR: Unicondylar Replacement

- PKA: Partial Knee Arthroplasty

- PKR: Partial Knee Replacement

- PCA: Partial Condylar Arthroplasty 
Page 5 of 33

\section{Introduction}

When end-stage osteoarthritis is isolated to one compartment of the tibio-femoral joint the patient is appropriate for UKR. Isolated lateral compartment osteoarthritis occurs in approximately $10 \%$ of arthritic knees [1, 2]. Whilst lateral UKR and Total Knee Replacement (TKR) are both reliable treatment options for end-stage osteoarthritis patients, UKR, which replaces only the damaged compartment and is ligament and bone conserving, may be the better choice in certain patient groups. $\mathrm{A}$ retrospective cohort study, comparing patients with lateral unicompartmental knee osteoarthritis receiving UKR or TKR, showed that UKR produced superior short-term functional outcomes compared with TKR, particularly in younger and in female patients[3].

UKR can either be mobile or fixed bearing. The theoretical advantages of the mobile bearing UKR over the fixed bearing UKR are: due to full congruency[4] of the mobile bearing there are lower contact stresses[5] and therefore lower polyethylene (PE) wear[6]. With decreased wear, there is less likely to be failure due to wear, the bearing can be thinner so bone can be preserved and there is preservation of knee kinematics in the long term[5]. Due to bearing mobility, there are minimal shear stresses at the bone-implant interface minimising the risk of loosening. The main disadvantage of mobile bearing UKR is bearing dislocation. On the medial side dislocation is rare, being about one in two hundred, and if it occurs it can usually be treated by inserting a new bearing[7]. In contrast, on the lateral side dislocation of the mobile bearing is much more common, because the lateral ligaments are lax in flexion allowing the joint to distract substantially. This has tempered its use in the lateral compartment [8]. 
Initially, the tibial component of mobile bearing lateral implants was similar to medial implants and had a flat tibial surface. More recently, the design of the tibial component was changed to have a spherically convex domed surface[9]. The objective of this modification was partly to more accurately restore the normal convex tibial surface to improve kinematics, particularly in high flexion, and partly to increase the distance the femoral and tibial components had to be distracted for the bearing to dislocate. To maintain full congruity with the spherical surfaces of the tibial and femoral components both articular surfaces of the bearing were spherically concave. This increased the "entrapment" of the bearing between the components and thus should decrease the dislocation rate[9].

At our centre, the change in the design of the tibial component from a flat articular surface to a domed articular surface appears to have decreased the incidence of dislocation. The extent by which this innovation has decreased dislocation more widely is unknown. Thus, the primary aim of this study was to establish the rate of mobile bearing dislocation of the flat tibial component compared with the domed tibial component. The study also aimed to compare the revision rate of the two designs. In addition, the study aimed to characterise the problem of mobile bearing dislocation in the lateral compartment of the knee by understanding the causes of dislocations, the mode of dislocation (either medially, laterally, anteriorly and posteriorly) and the possible risk factors.

\section{Materials and methods}

\subsection{Search strategy}

Three electronic databases, MEDLINE, EMBASE and ISI Web of Science, were searched to identify studies reporting on the outcomes of mobile bearing Oxford 
lateral UKR (Zimmer Biomet, Warsaw, IN). The search strategy was implemented in MEDLINE and EMBASE on the $15^{\text {th }}$ March 2019 and repeated on the $25^{\text {th }}$ May 2020. For ISI Web of Science, the search was conducted on the $22^{\text {nd }}$ June 2020. Additionally, a manual internet search was conducted on the $15^{\text {th }}$ March 2019 and the $22^{\text {nd }}$ June 2020 . For all searches, we also obtained the reference list of retrieved articles and systematic reviews captured by the search. The search strategy started with a relevant MESH term, followed by all synonyms for the concept of partial knee replacement and mobile bearing. Then, specific search terms regarding (1) bearing dislocation, (2) failure, (3) bearing and (4) mobile were searched (see Appendix D:

Search Strategy). Search strings were built in MEDLINE and subsequently modified for EMBASE and ISI Web of Science. The search strategy was developed in conjunction with an experienced librarian, and the research team members who have experience in systematic reviews in this area of research. No date limit or language restrictions were imposed on the search results. The reference list of relevant systematic reviews captured by the search were reviewed for eligible studies for inclusion. The reference list of the final list of included studies were also reviewed for eligible studies.

\subsection{Selection criteria for studies}

All studies containing patients treated with either the flat or the domed implants and their outcomes were included in the systematic review. These included: Randomised Control Trials (RCTs), cohort studies, case control studies, case series.

All reviews were excluded. Any studies assessing radiographic imaging or conducted in animals, models (mechanical and computational), and in vitro were excluded from the review. Editorials/expert opinions were not included and case reports were also 
excluded because the assessment of dislocation rate was a primary aim. Studies on registry data were excluded due to insufficient data specific to lateral mobile bearing UKRs. Wherever possible, the speculative causes for dislocations, and other relevant findings such as associations identified radiographically or through mechanical models were summarised and reported narratively under the discussion section.

\subsection{Data collection}

The findings were exported with full references to Endnote (version $\geq X 8$, Clarivate Analytics) and duplicate entries were removed. Following this, titles and abstracts were independently screened and discrepancies were resolved by review authors, IY and TWH. All authors were then sent the final list of included studies for agreement. Data extraction of the included studies was conducted by IY and TWH independently with disputes resolved by SJM or DWM.

For each study, where possible, the following information was extracted: First author, publication date, country of study, study type, level of evidence, total number of knees operated, total number of patients, number of male patients, number of female patients, mean age (years), age range of patients, study start date, study end date, number of surgeons, surgeon type (either designer or independent), surgical technique used, mean follow up duration (months), follow up range (months), number of bearing dislocations reported, mode of dislocation (anterior, posterior, medial, lateral), cause(s) of the dislocations, how the dislocation was resolved, time of dislocation (months), implant survival with dislocation as the endpoint.

\subsubsection{No. of patients followed up}


With regards to the number of patients followed up, this was calculated by taking the total number of patients and subtracting the number of patients lost to follow up and those who had refused to participate. It was decided to include the patients who had died into the analysis as most clinical records would have information regarding patient knee revision status.

Where data was missing or incomplete, we attempted to contact study authors to obtain this where possible. All statistical analyses were conducted using Stata, version 13 (StataCorp, College Station, TX) with $p<0.05$ considered statistically significant.

\subsection{Strategy for data synthesis}

\subsubsection{Statistical analysis}

As revision rates follow a binomial distribution, a meta-analysis of proportions was performed (metaprop command in Stata). Using the metaprop command ensured that studies with $0 \%$ or $100 \%$ proportions were included in the meta-analysis. The summary dislocation incidence or annual revisions were pooled using a randomeffects model to minimize the effect of between-study heterogeneity. The $I^{2}$ statistic assessed the percentage of total variation due to inter-study heterogeneity.

The primary comparison between flat and domed tibial components was dislocation, which was assessed either as a rate (number of dislocations/number of cases, expressed as \%) or as an annual rate (\%pa) calculated by the Patient Time Incidence Rate (PTIR) method[12]. The PTIR analysis is based on the assumption that the event rate is constant over time. Previous studies have suggested that this is not the case for dislocation, as dislocations tend to occur in the first year. If this study has the same finding then dislocation would be best assessed by rate rather than 
annual rate (PTIR). PTIR determines the number of events per 100 component years. It is calculated by dividing the number of events by the total number of cases multiplied by the average follow up and is expressed as a percentage.

The PTIR method was used to assess revisions as these tend to be relatively constant over time. The annual revision rate was calculated for two different endpoints: all cause revision and revisions excluding those occurring as a result of dislocation; with data grouped by flat or domed tibial component design. PTIR was also used for the subgroup analyses such as designer versus non-designer and gender (male versus female). Survival rates were estimated by multiplying the annual failure rate by the number of years for the survival estimate and then subtracting this from 100.

\subsubsection{Confidence interval}

For both rates and annual rates, the $95 \%$ Confidence Intervals (Cls) were calculated using the Clopper-Pearson or exact binomial method for a binomial proportion. This is computed by inverting the equal-tailed test based on the binomial distribution. This calculation also incorporates the Freeman-Tukey double arcsine transformation of proportions, which enables the within-study variability to be modelled using the binomial method, and functions to stabilise the variance. This was necessary since revisions due to bearing dislocation were expected to be low.

\subsection{Risk of bias assessment}

A modified method of assessing bias, previously reported by Campi et al. [10] and de Vos-Kerkhof et al.[11], was used to assess the level of bias in each of the included studies. The modified method uses the Methodological Index for evaluation of NonRandomized Studies (MINORS) and an additional scoring system based on the 
Page 11 of 33

presence of primary outcome reporting $(A=$ clearly reported, $B=$ nonreported/unclear) and the number of cases in the studies $(A>100, B=51-99, C=<$ $50)[10,12]$. Studies with a MINORS score over $80 \%$ were considered at low risk of bias and those below $70 \%$ at high risk (except those with 3 or more "As" in outcome reporting and study size[10]).

3. Due to the low number of studies, which met the inclusion criteria, it was decided not to eliminate any studies due to high risk of bias, but rather to report the risk of bias, and to exercise caution in data interpretation and when reporting conclusions. Where possible, meta-analyses were reported whereby specific studies at high risk of bias and most likely to affect results, were removed to see effects on the overall results. Further, the risk of bias across studies was not assessed, due to the low volume of studies available for review, and the limited benefit that this would provide the review.

\section{4.}

\section{Results}

Searches identified 7405 articles, with an additional 10 manually identified studies. After duplicates were removed, 5050 articles remained. After screening, 21 full texts articles were retrieved and assessed. From the assessment, 12 texts were excluded (see Table B. 1 in Appendix A), leaving 9 studies which met the inclusion criteria (see Figure 1 below). The 9 included studies consisted of three flat tibial component design series, and six domed tibial component design series. Of the three flat series studies, all were retrospective cohort studies. Of the six domed series studies, five studies were retrospective cohort studies and one prospective cohort study.

Reasons for excluding studies are listed in Table B. 1. All studies were included in the quantitative analysis for the primary outcome of mobile bearing dislocation. 


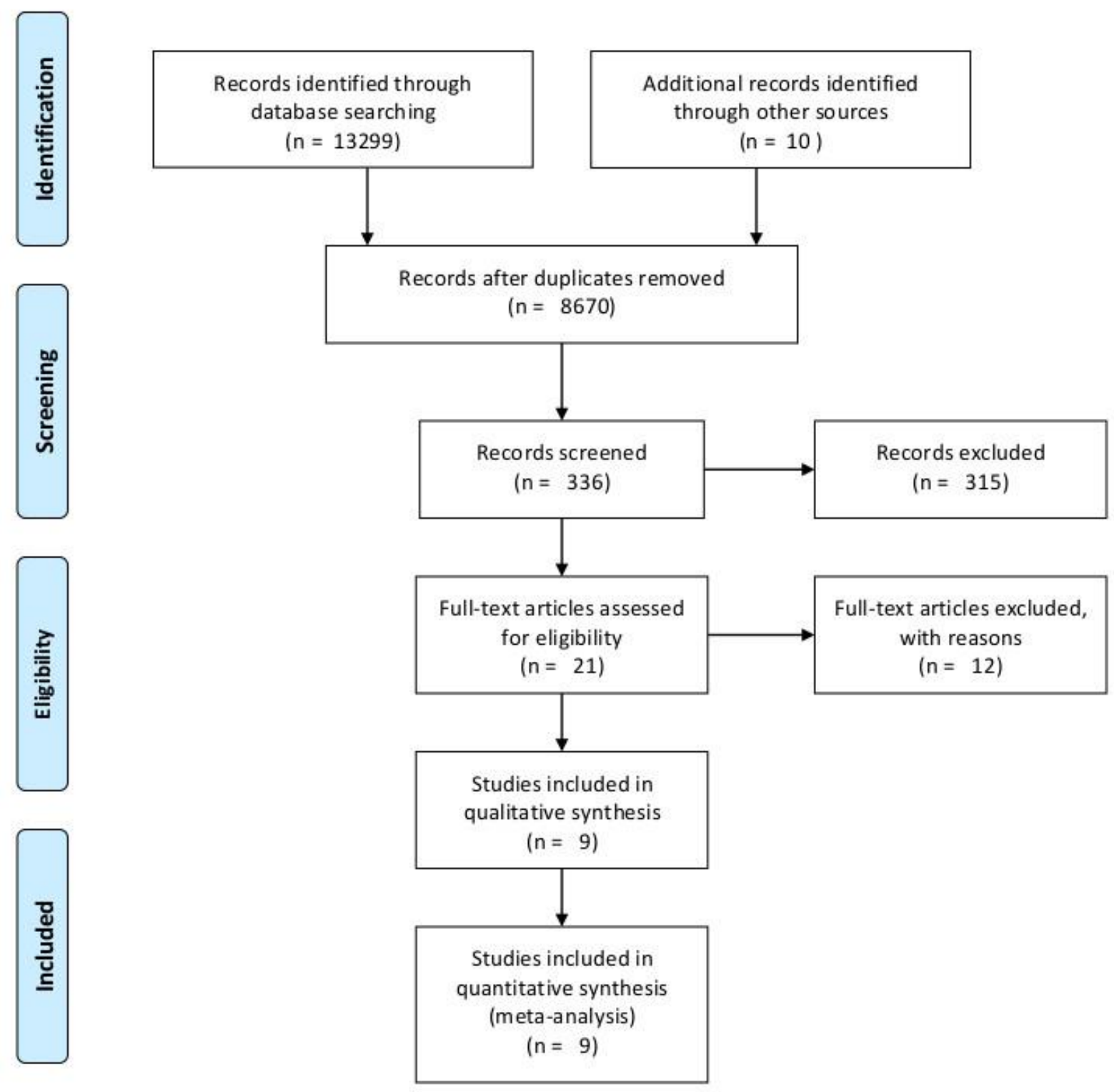

Figure 1. PRISMA flow diagram for study inclusion.

Using the modified method of assessing bias, previously reported by Campi et al.

[10] and de Vos-Kerkhof et al. [11], the level of bias in each of the studies included in quantitative data synthesis revealed five series at high risk of bias and four series with low risk of bias (see Table C. 1 in ). 
Page 13 of 33

Table 1. Demographic information of studies included in quantitative analysis.

\begin{tabular}{|c|c|c|c|c|c|c|c|c|c|}
\hline Author & Year & Country & Study type & $\begin{array}{l}\text { Total } \\
\text { no. of } \\
\text { knees }\end{array}$ & $\begin{array}{l}\text { Total no. } \\
\text { of patients }\end{array}$ & $\begin{array}{c}\% \text { Male } \\
\text { patients } \\
\text { (no.) }\end{array}$ & $\begin{array}{c}\% \text { Female } \\
\text { patients } \\
\text { (no.) }\end{array}$ & $\begin{array}{l}\text { Mean } \\
\text { age }\end{array}$ & $\begin{array}{l}\text { Age } \\
\text { range }\end{array}$ \\
\hline \multicolumn{10}{|c|}{ Flat tibial component } \\
\hline Kehr[13] & 1995 & France & $\begin{array}{c}\text { Retrospective } \\
\text { cohort }\end{array}$ & 5 & 3 & $\begin{array}{l}\text { None } \\
\text { stated }\end{array}$ & $\begin{array}{l}\text { None } \\
\text { stated }\end{array}$ & $\begin{array}{l}\text { None } \\
\text { stated }\end{array}$ & $\begin{array}{l}\text { None } \\
\text { stated }\end{array}$ \\
\hline Gunther[1] & 1996 & UK & $\begin{array}{c}\text { Retrospective } \\
\text { cohort }\end{array}$ & 53 & 51 & $8(4)$ & $92(47)$ & 68 & $40-88$ \\
\hline Pandit[14] & 2010 & UK & $\begin{array}{l}\text { Retrospective } \\
\text { cohort }\end{array}$ & 65 & 64 & $44(28)$ & $56(36)$ & 53 & $39-83$ \\
\hline \multicolumn{10}{|c|}{ Domed tibial component } \\
\hline Schelfaut[15] & 2013 & Belgium & $\begin{array}{c}\text { Prospective } \\
\text { cohort }\end{array}$ & 25 & 25 & $36(9)$ & $64(16)$ & 60 & $31-86$ \\
\hline Marson[16] & 2014 & UK & $\begin{array}{c}\text { Retrospective } \\
\text { cohort }\end{array}$ & 15 & $\begin{array}{l}\text { None } \\
\text { stated }\end{array}$ & $\begin{array}{l}\text { None } \\
\text { stated }\end{array}$ & $\begin{array}{l}\text { None } \\
\text { stated }\end{array}$ & 58 & $41-77$ \\
\hline Newman[17] & 2017 & UK & $\begin{array}{c}\text { Retrospective } \\
\text { cohort }\end{array}$ & 64 & 58 & $29(17)$ & $71(41)$ & 71 & $44-92$ \\
\hline Fornell[18] & 2018 & Spain & $\begin{array}{c}\text { Retrospective } \\
\text { cohort }\end{array}$ & 41 & 41 & $29(10)$ & $71(31)$ & 63 & $38-81$ \\
\hline \multirow{4}{*}{ Walker[19] } & \multirow{4}{*}{2018} & Germany & \multirow{4}{*}{$\begin{array}{l}\text { Retrospective } \\
\text { cohort }\end{array}$} & 344 & 327 & $24(90)$ & $76(237)$ & 65 & $36-88$ \\
\hline & & Heidelberg* & & 120 & 114 & $28(32)$ & $62(82)$ & $\begin{array}{l}\text { None } \\
\text { stated }\end{array}$ & $\begin{array}{l}\text { None } \\
\text { stated }\end{array}$ \\
\hline & & $\begin{array}{c}\text { Bad } \\
\text { Rappenau* }\end{array}$ & & 32 & 31 & $35(11)$ & $65(20)$ & $\begin{array}{l}\text { None } \\
\text { stated }\end{array}$ & $\begin{array}{l}\text { None } \\
\text { stated }\end{array}$ \\
\hline & & Stuttgart* & & 192 & 182 & $26(47)$ & 74 (135) & $\begin{array}{l}\text { None } \\
\text { stated }\end{array}$ & $\begin{array}{l}\text { None } \\
\text { stated }\end{array}$ \\
\hline Kennedy[20] & 2020 & UK & $\begin{array}{c}\text { Retrospective } \\
\text { cohort }\end{array}$ & 325 & 308 & 34 (104) & $66(204)$ & 65 & $39-90$ \\
\hline \multicolumn{4}{|c|}{ TOTAL } & 937 & 877 & $30(262)$ & $70(612)$ & $\begin{array}{c}63 \\
(64 * *) \\
\end{array}$ & N/A \\
\hline
\end{tabular}

*Sub study breakdown by location within Germany.

${ }^{* *}$ Mean weighted age. Excluded the Kehr et al.[13] studydue to insufficient information.

From the data, more women (70\%) suffer from lateral compartment disease than men $(30 \%)$

Table 2. Dislocation with patient specific information available: summary findings.

\begin{tabular}{|c|c|}
\hline $\begin{array}{c}\text { Dislocations with dislocator age info. } \\
\text { Available }\left(\%^{*}\right)\end{array}$ & $21(35)$ \\
\hline Average age of dislocators in years (range) & $61(39-84)$ \\
\hline Dislocations with sex info. available $\left(\%^{*}\right)$ & $22(37)$ \\
\hline Number male dislocators $\left(\%^{\star \star}\right)$ & $9(41)$ \\
\hline Number female dislocators $\left(\%^{\star *}\right)$ & $13(59)$ \\
\hline $\begin{array}{c}\text { Mean time of dislocation (n=28) (range) } \\
\text { (months) }\end{array}$ & $16(0.6-104.4)$ \\
\hline
\end{tabular}


Page 14 of 33

${ }^{*}$ Percentages have been calculated with respect to the total number of dislocations ( $n=60)$ across all studies.

${ }^{* *}$ Percentage out of the total who have reported

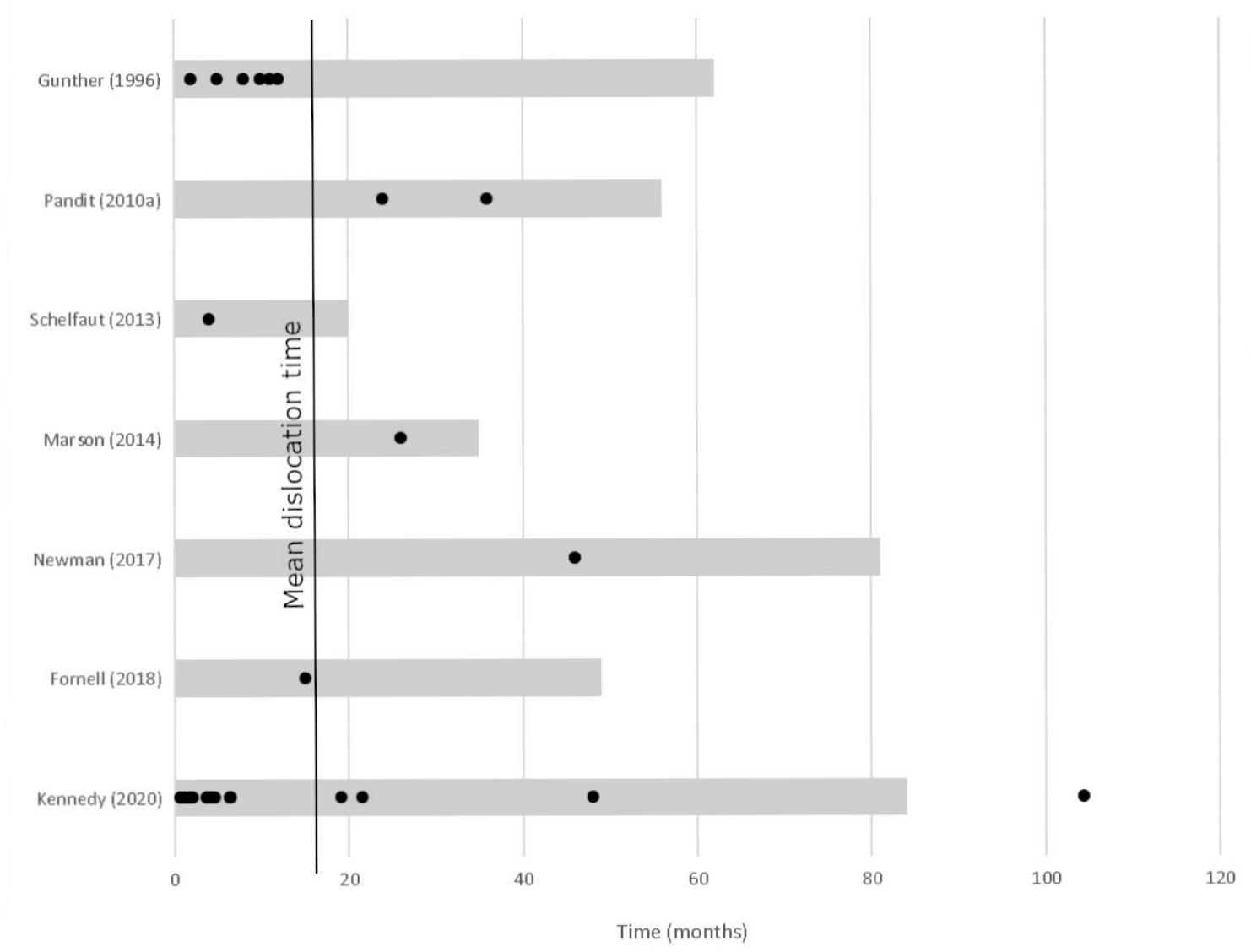

Mean follow-up period Dislocations

Figure 2. Time of first dislocation(s) with respect to the mean follow up duration (months). The mean time of first dislocation (16 months) is marked and labelled.

From the included studies, 21 dislocations reported the patient age (35\% of total number of dislocations) (see Table A. 2). The average age of patient with a dislocation was 61 years old (range 39 - 84). Similarly, using the 22 dislocations with gender reported (37\% of total number of dislocations) (see Table A. 2 ), more women $(59 \%)$ dislocate than men (41\%). 
Page 15 of 33

Table 3. Mobile bearing dislocation data for all studies reporting no. of dislocations.

\begin{tabular}{|c|c|c|c|c|c|c|}
\hline Author (Year) & $\begin{array}{l}\text { Total } \\
\text { no. of } \\
\text { knees }\end{array}$ & $\begin{array}{c}\text { Mean follow } \\
\text { up duration } \\
\text { (months) }\end{array}$ & $\begin{array}{l}\text { No. bearings } \\
\text { dislocated }\end{array}$ & Dislocation risk (\%) & $\begin{array}{c}\text { No. of } \\
\text { asymptomatic } \\
\text { bearing } \\
\text { subluxations }\end{array}$ & $\begin{array}{c}\text { Dislocation mode (\% } \\
\text { of the total) }\end{array}$ \\
\hline \multicolumn{7}{|c|}{ Flat tibial component } \\
\hline Kehr (1995)[13] & 5 & 39 & 4 & 80 & None Stated & None stated \\
\hline $\begin{array}{l}\text { Gunther } \\
\text { (1996)[1] }\end{array}$ & 53 & 62 & 6 & 11 & None Stated & None stated \\
\hline $\begin{array}{l}\text { Pandit } \\
(2010)[14]\end{array}$ & 65 & 56 & 3 & 5 & None Stated & $\begin{array}{c}67 \% \text { medial } \\
\text { dislocations into the } \\
\text { intercondylar notch.* }\end{array}$ \\
\hline \multicolumn{7}{|c|}{ Domed tibial component } \\
\hline $\begin{array}{l}\text { Schelfaut } \\
\text { (2013)[15] }\end{array}$ & 25 & 20 & 1 & 4 & None Stated & $\begin{array}{c}100 \% \text { Medial } \\
\text { dislocation into the } \\
\text { intercondylar notch. }\end{array}$ \\
\hline $\begin{array}{l}\text { Marson } \\
(2014)[16]\end{array}$ & 15 & 35 & 1 & 7 & None Stated & None Stated \\
\hline $\begin{array}{l}\text { Newman } \\
(2017)[17]\end{array}$ & 64 & 81 & 1 & 2 & None Stated & None Stated \\
\hline $\begin{array}{c}\text { Fornell } \\
(2018)[18]\end{array}$ & 41 & 49 & 1 & 2 & None Stated & $\begin{array}{l}100 \% \text { Medial } \\
\text { dislocation }\end{array}$ \\
\hline $\begin{array}{c}\text { Walker } \\
(2018)[19]\end{array}$ & 344 & 37 & 19 & 6 & 1 & None Stated \\
\hline $\begin{array}{l}\text { Kennedy (2020) } \\
\text { [20] }\end{array}$ & 325 & 84 & 14 & 4 & None Stated & $\begin{array}{c}71 \% \text { medial } \\
\text { dislocations } \\
14 \% \text { unknown } \\
14 \% \text { anterior } \\
\text { dislocations }\end{array}$ \\
\hline
\end{tabular}

${ }^{\star}$ Remaining dislocation modes not mentioned.

From the clinical reports included in this meta-analysis, in the four papers where the mode of dislocation was reported, all had indicated that at least 1 of the dislocations were medial into the intercondylar notch with the bearing lodged on top of the wall of the tibial component. Of the flat series, it was only the Pandit et al. [14] publication, which had stated the mode of dislocation and this was reported as medially. Of the nine studies comprising the domed series, three studies $[15,18,20]$ had reported the mode of dislocation as medial dislocations, aside from two anterior dislocations reported by Kennedy et al.[20]. 


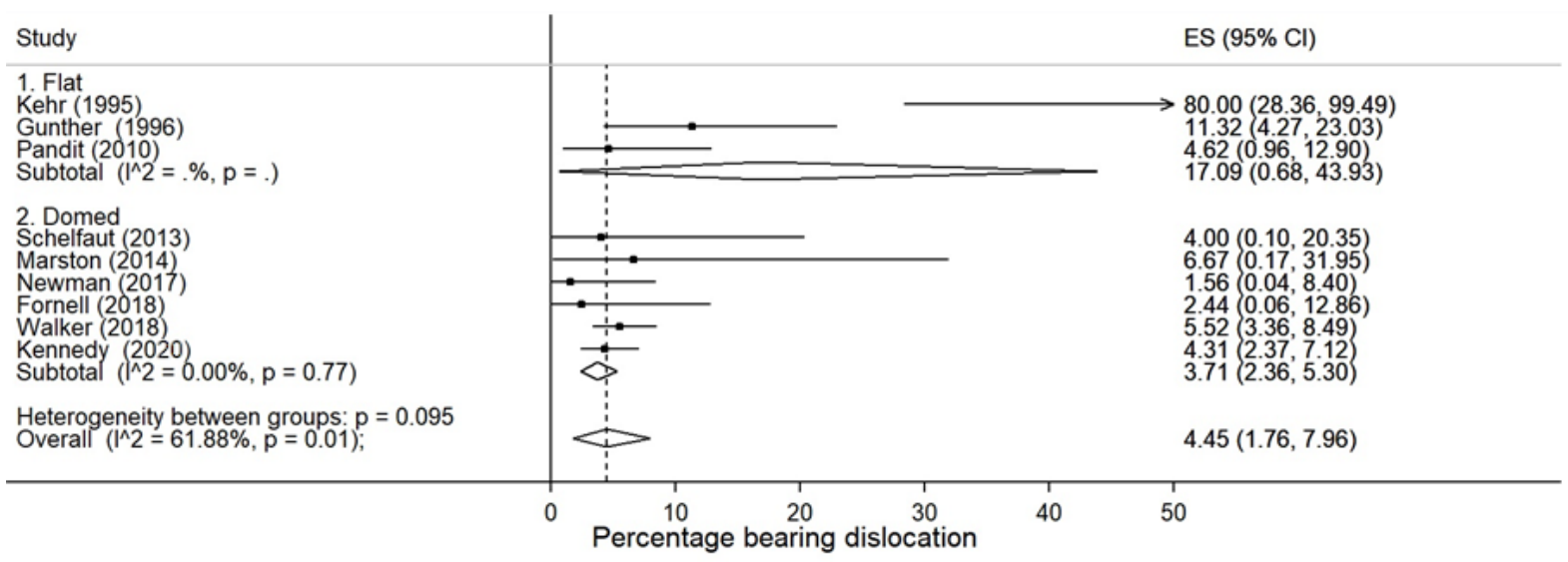

Figure 3. Percentage bearing dislocation assessment of flat versus domed tibial component design.

The overall incidence of bearing dislocation in both flat and domed tibial designs was $4.5 \%$ (Figure 3). Changing the design of the tibial component from flat to domed decreased the dislocation rate from $17 \%(95 \% \mathrm{Cl}: 0.68-43.93)$ in the flat to $3.7 \%$ $(95 \% \mathrm{Cl}: 2.36-5.30)$ in the domed series. The large confidence interval seen in the flat series is largely attributed to the Kehr et al.[13] study. Removing the Kehr study from the analysis reduces the dislocation rate for the flat tibial tray design to $7.3 \%$ $(95 \% \mathrm{Cl}: 3.08-12.91)$, but it is still higher than that for the domed component (Figure 4).

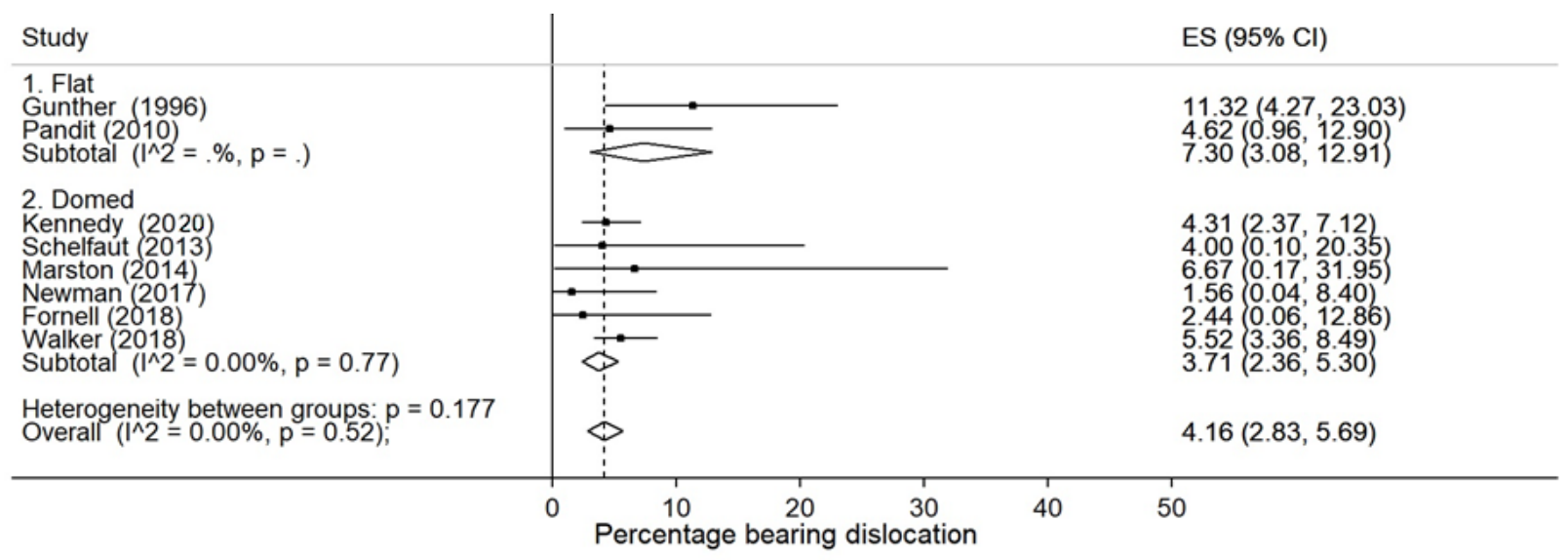


Page 17 of 33

Figure 4. Percentage bearing dislocation assessment of flat versus domed tibial

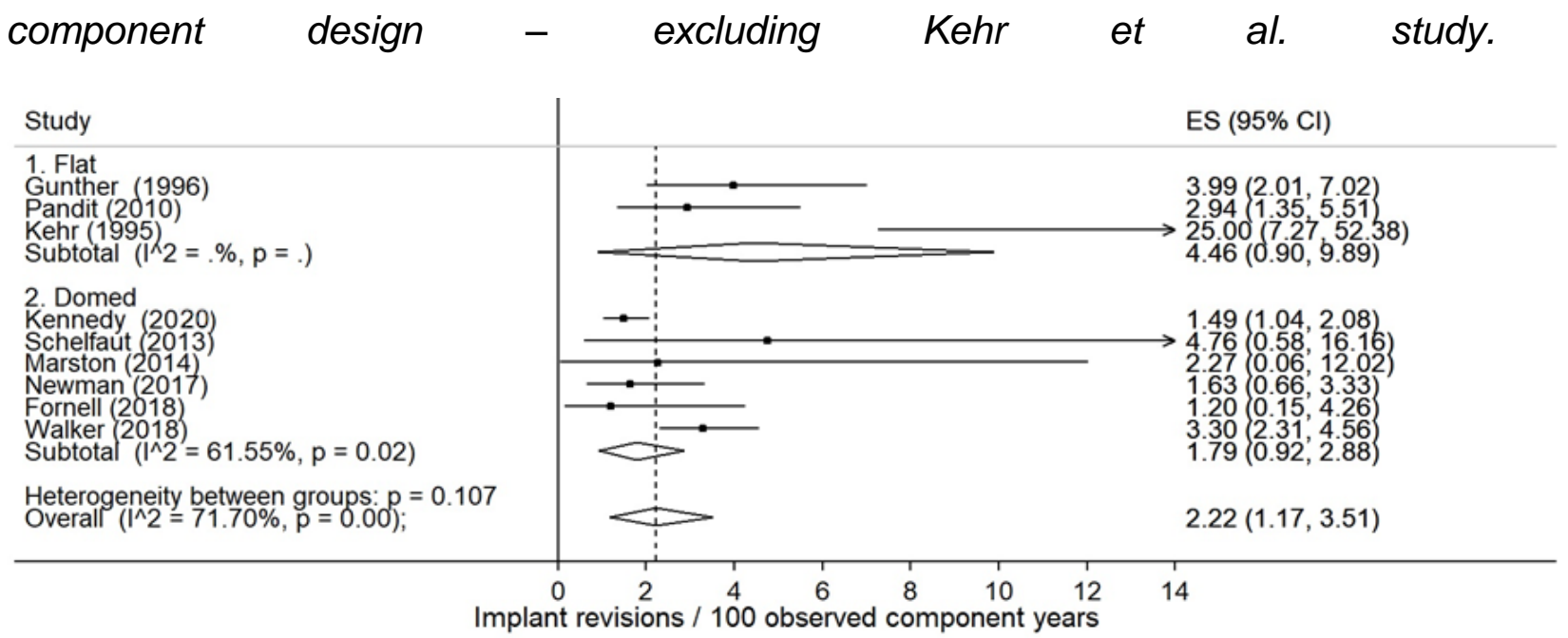

Figure 5. PTIR assessment for all cause revision: Flat versus domed tibial component.

The PTIR for all cause revision for the flat tibial tray was $4.5 \%$ pa, equivalent to a five-year revision rate of $22 \%$. For the domed tibial tray, it was $1.8 \%$ pa, equivalent to a five-year revision rate of $9.0 \%$.

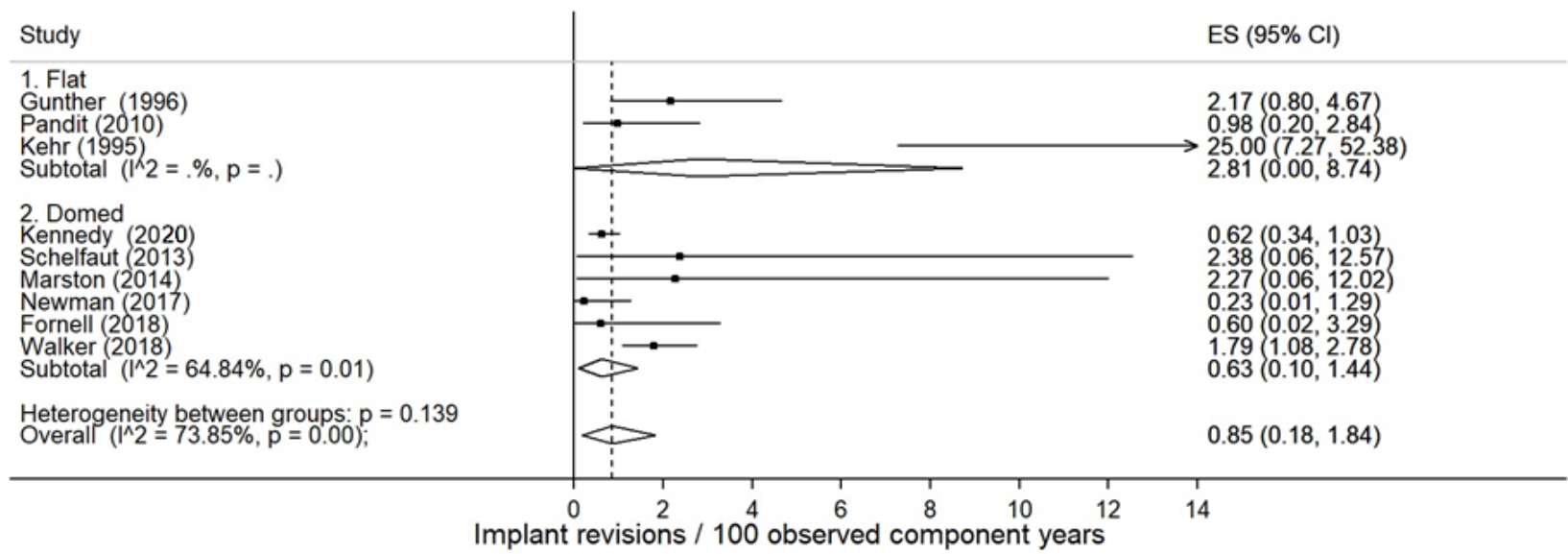

Figure 6. PTIR assessment of bearing dislocation: flat versus domed tibial component design.

The PTIR for bearing dislocation for the flat tibial tray was $2.8 \%$ pa, equivalent to a fiveyear dislocation rate of $14 \%$ (Figure 6 ). For the domed tibial tray, the PTIR for 
dislocation was $0.6 \%$ pa, equivalent to a five-year dislocation rate of $3 \%$.

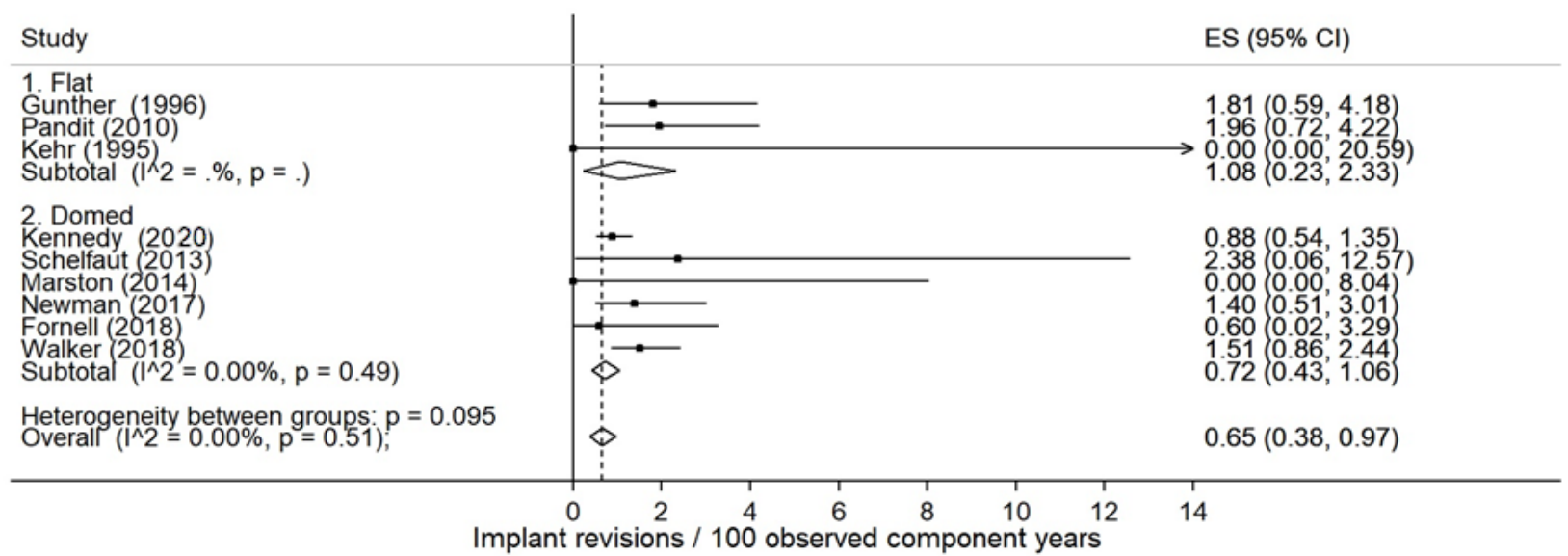

Figure 7. PTIR assessment for all cause revision except bearing dislocation: Flat versus domed tibial component.

The PTIR for revision excluding dislocation for the flat tibial tray was $1.1 \%$ pa, equivalent to a five-year revision rate of $5.5 \%$. For the domed tibial tray it was $0.7 \%$ pa, equivalent to a five-year revision rate of $3.6 \%$.

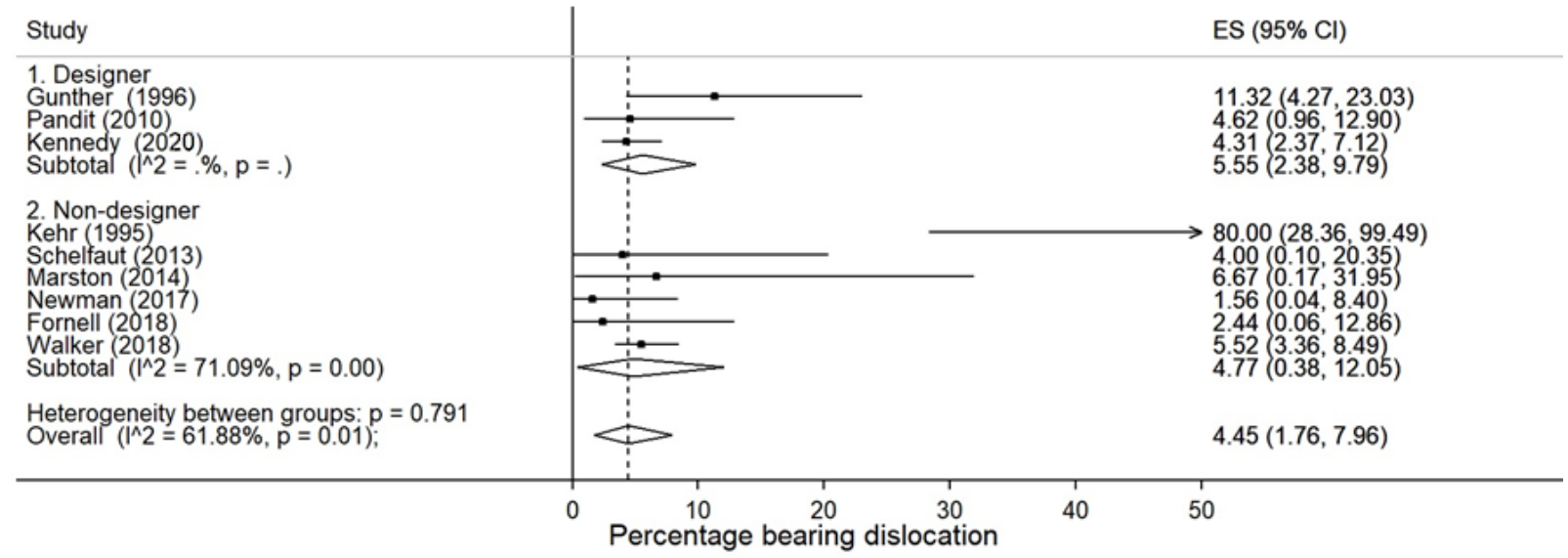

Figure 8. Percentage bearing dislocation: designer versus non-designer.

Subgroup analysis by designer versus non-designer showed no difference $(p=0.791)$. 
Page 19 of 33

\section{Discussion}

We identified nine studies that met the inclusion criteria for this review: three were studies reporting on the clinical outcomes using the flat tibial component, and the remaining six studies reported on the clinical outcomes using the domed tibial component. This study assessed dislocation both in terms of the absolute rate and the annual rate. However as dislocations tended to occur early, with the average time to dislocation being 16 months post operatively, the best way to assess dislocation was with the overall rate rather than the annual rate.Without accounting for bias, thisstudy identified that changing the design of the tibial component from a flat tibial tray to a domed tibial tray has reduced the dislocation rate from $17 \%$ to 3.7\%. After removing the Kehr et al.[13] study, which was an outlier with four dislocations out of five operated knees and which contributed to the large confidence interval seen in the flat tibial tray series, ( Figure 4), the dislocation rate for the flat tibial tray series reduced from $17 \%$ to $7.3 \%$, which is still higher than the $3.7 \%$ for the domed tibial tray series.

This study also assessed revision based on the annual rate. The annual rate was calculated using the PTIR method in accordance with routine practice of the National Joint Registry (NJR)[21]. The change from flat to dome tibia decreased the annual revision rate by about two thirds. It also decreased the annual revision rate, excluding revisions for dislocation, by about one third suggestingthat the dome tibia has other advantages beyond dislocation compared to the flat, which probably relate to its more anatomical shape and better kinematics. Although we were unable to compare patient functional outcome in this study, the evidence from the literature suggests that the change from flat to dome did not compromise patient outcome and the dome tibia has achieved consistently good results when assessed with the 
Oxford Knee Score[14]. Further, there is evidence to suggest the functional results of the dome were better than those of the flat, with an improved range of movement and more normal kinematics [22].

The annual revision rate, excluding dislocation, for the dome tibia was $0.7 \%$ pa, which equates to a ten year survival of about $93 \%$. With an additional $3.7 \%$ revision rate due to dislocation the ten year survival would be about $90 \%$, which is acceptable. However, if the dislocation rate could be reduced further it would be beneficial. The study found no difference in dislocation rate between designer and non-designer surgeons. .

\subsection{Dislocation mode}

The reason why mobile bearing dislocations are common following lateral rather than medial UKR is that the lateral ligaments become lax in knee flexion[25]. As a result, the lateral compartment can distract in flexion allowing the bearing to dislocate[26].As the mobile bearing is unconstrained, it can theoretically dislocate in any direction: anteriorly, posteriorly, medially and laterally. Lateral dislocation has not been reported clinically. This is presumably because, when the lateral compartment is distracted and a dislocation might occur, the lateral soft tissues are tight and prevent the bearing from escaping laterally. Our study found that, whilst anterior dislocations can occur rarely, medial dislocation is the most common mode of dislocation and is often described as the bearing dislocating into the intercondylar notch $[14,15,18,20]$. This is presumably because the entrapment for medial dislocation is less than for anterior dislocation. It may also be partly because the distance the bearing has to move to dislocate is less for a medial dislocation than an anterior or posterior dislocation. In general, it was not possible to ascertain the 
Page 21 of 33

proportions of different modes of dislocation, since many reports do provide this information.

\subsection{Cause of dislocation}

Some studies reported what the patient was doing when they think they dislocated and what they suspected to be the cause of dislocation. Some patients reported a traumatic incidence which may have led to their dislocation (e.g. a fall[17], falling off a bus[18], falling down the stairs[27], stepping into a rabbit hole[27], or squatting[28]), and sometimes, this was associated with damage to the Anterior Cruciate Ligament (ACL) and Lateral Collateral Ligament (LCL) [14, 20]. Whilst there was insufficient data to ascertain the definitive cause of dislocation, all dislocated knees were reportedly in a position such that the lateral compartment of the knee was unloaded and in flexion (subject to trauma), and therefore, could be distracted. Although women were more likely to have lateral UKR than Men (70\% versus 30\%) Table 1), the risk of dislocation was not related to gender (Figure 8).

\subsection{Treatment of dislocations}

Dislocations are usually associated with immediate symptoms, although the nature of these symptoms were not described. However, occasionally patients are asymptomatic[19, 29] and, if diagnosed, have occasionally been treated conservatively[29]. Usually, symptomatic dislocations have been successfully treated by bearing exchange whereby the dislocated bearing is removed and a new bearing, of the same thickness or thicker, is inserted. In addition, the bearing and knee are examined for evidence of impingement of bone or cement on the bearing and if this is found it is addressed $[1,14,19,20,30]$. There are occasional reports of closed reduction of the bearing under general anaesthesia and anecdotal reports of 
reduction under local anaesthesia[16] $[17,18]$. There is insufficient evidence to determine the precise rate of recurrent dislocation, but the evidence that exists suggests that it is about one in three[1, 17, 19, 20, 29]. For primary dislocation, particularly if there are other problems, or for recurrent dislocation conversion to TKR is often undertaken[31]. There are other options: Screws have been inserted into the tibial eminence, with their heads positioned above the tibial wall to augment the tibial wall height, with the goal being to further prevent medial dislocations[14]. Some have reported success with this procedure[14, 15], however, some concern around possible complications have also been expressed[14]. Following introduction of the fixed lateral Oxford (FLO) UKR, which can be used interchangeably with the mobile, revision of the mobile tibia to the FLO is probably now the best and most commonly used treatment [19, 32].

\subsection{Addressing the problem of mobile bearing dislocation}

The problem of bearing dislocation could potentially be addressed by improving the surgical technique, the implant design, and patient selection. In the flat tibial component series, the dislocation rates were reduced by improving the surgical technique[14]. It is not clear what further modifications to the technique would help. The change in design from flat to dome with increased entrapment also decreased the dislocation rate, and perhaps further modifications that increase entrapment may reduce the dislocation rate further. The introduction of the FLO allows surgeons to decide intra-operatively whether to use a mobile of fixed bearing. With trial dome components in place and the knee in a figure of four position the surgeon can assess how easily the trial bearing can be subluxed into the intercondylar notch. If this is difficult, a dome tibia and mobile bearing can be implanted otherwise it would be sensible to implant a FLO tibia. 
Page 23 of 33

\subsection{Study limitations}

We used a comprehensive broad search strategy, and searched the reference lists of potentially relevant studies and reviews, and conducted manual searches in order to identify all relevant studies. However, there are a number of limitations with this study.Firstly, isolated lateral unicompartmental disease is relatively rare, accounting for $10 \%$ of all arthritic knees [2]. Therefore, few lateral UKR are implanted and few publications are available for inclusion in a systematic review. As a result there were only 937 patients in our review, so it was inadequately powered for formal statistical comparisons between groups, we had to deviate from the proposed PROSPERO analysis (see Systematic review registration). Due to the low number of studies available, our confidence in the dislocation rate estimate reported is limited due to the low volume of evidence available and the true dislocation rate may be different from our estimate. Further, it was decided not to eliminate studies based off level of bias nor to calculate the overall bias across studies due to the limited benefit this would bring. Instead, in addition to reporting the dislocation results for all studies, we also present the dislocation results after selectively eliminating the Kehr et al.[13] study, which was an outlier with a dislocation rate far higher than any of the other included studies (four dislocation out of five operated knees). Even after eliminating the Kehr study, the dislocation rate for the flat tibial series was still double that of the domed series. There was limited data for outcomes of interest: country of study, surgeon case-load, male versus female dislocation. Therefore, it was decided to summarise this information reported, but not used it for subgroup analysis. Wherever possible, we also exercised caution in data interpretation and when reporting conclusions. Furthermore, publications are likely to be from high volume centres, which may limit the generalisability of the results. However, there was no evidence 
Page $\mathbf{2 4}$ of $\mathbf{3 3}$

that the designer surgeons, who published many of the papers, had different results to the non-designer surgeons. Due to the limited data we were unable to do a formal survival and to assess functional outcomes.

\section{Conclusions}

Our study has shown that changing the design of the mobile bearing lateral UKR tibial component from flat to domed has reduced the bearing dislocation rate from $17 \%$ to $3.7 \%$. With the option to change from mobile to fixed bearing intra-operatively if there is marked bearing instability, the dislocation should drop further. The study also showed that the change to the dome tibia reduced the revision rate excluding dislocation by about one third. With the dome tibia the annual revision rate, excluding dislocation, was $0.7 \% \mathrm{pa}$, which equates to a ten year survival of about $93 \%$.

\section{Systematic review registration}

PROSPERO number CRD42019139250.

\section{Acknowledgements}

IY would like to thank the Clarendon Fund, Oxford University Press at University of Oxford for funding her DPhil studies. Acknowledgement goes to Hasan R. Mohammad from the Oxford Orthopaedic Engineering Centre (OOEC) and Catherine Hartley of the Nuffield Orthopaedic Library who kindly assisted in building the search strategy for this systematic review. The authors also want to thank Mr. Jules Morel for translation and Mrs Barbara. E. Marks and Mr. James Kennedy for their assistance with this study. The study has been supported by the University of

Oxford. Institutional funding has been received from Zimmer Biomet. 
Page 25 of 33

\section{Conflict of Interest Statement}

The author or one of more of the authors have received or will receive benefits for personal or professional use from a commercial party related directly or indirectly to the subject of this article. In addition, benefits have been or will be directed to a research fund, foundation, educational institution, or other non-profit organisation with which one or more of the authors are associated.

\section{Appendices}

\subsection{Appendix A}

Table A. 1.PICOS outline to define the systematic review question.

\begin{tabular}{|c|c|}
\hline Population & $\begin{array}{l}\text { Adult patients }(>18 \mathrm{y} / 0) \text { with lateral compartment knee osteoarthritis } \\
\text { refractory to non-surgical treatment. }\end{array}$ \\
\hline Intervention & Surgical treatment using either the flat or the domed OUKR implant. \\
\hline Comparators & $\mathrm{N} / \mathrm{A}$ \\
\hline Outcomes & $\begin{array}{l}\text { Primary outcomes } \\
\text { - Dislocation rate (see Strategy for data synthesis for calculation } \\
\text { methods) } \\
\text { Secondary outcomes } \\
\text { - Dislocation mode: anterior, posterior, medial or lateral } \\
\text { - Cause(s) of the dislocations } \\
\text { - How the dislocation was resolved } \\
\text { - Time of dislocation (early <12months post surgery, medium } \\
>12 \text { months }<2 \text { years, late }>2 \text { years } \\
\text { - Implant survival with dislocation as the endpoint } \\
\underline{\text { Sub-group stratification categories }}\end{array}$ \\
\hline
\end{tabular}




\begin{tabular}{|l|l|}
\hline & $\begin{array}{l}\text { If data permits, subgroup analyses will be conducted to compare } \\
\text { the effect estimate between studies that evaluate: } \\
\text { Country of study } \\
\text { Surgeon type: designer versus independent } \\
\text { Surgeon case-load } \\
\text { Study design }\end{array}$ \\
$\begin{array}{l}\text { Included: Randomised Control Trials (RCTs), cohort studies, case } \\
\text { control studies, case series } \\
\text { Excluded: paediatric cohort (<18y/0), reviews, animal studies, } \\
\text { mechanical model studies, cadaveric studies, editorials/expert } \\
\text { opinions, case reports, registry-based studies. }\end{array}$ \\
\hline
\end{tabular}

Table A. 2.Dislocation with patient specific information available.

\begin{tabular}{|c|c|c|c|c|c|}
\hline Study & $\begin{array}{c}\text { Dislocation } \\
\text { number }\end{array}$ & $\begin{array}{l}\text { Mean follow up } \\
\text { duration (mo) }\end{array}$ & $\begin{array}{c}\text { Time of } \\
\text { dislocation (mo) }\end{array}$ & Gender & $\begin{array}{c}\text { Patient age } \\
\text { (yrs) }\end{array}$ \\
\hline \multirow{6}{*}{ Gunther[1] } & 1 & \multirow{6}{*}{62} & 11 & Female & 82 \\
\hline & 2 & & 10 & Female & 78 \\
\hline & 3 & & 5 & Male & 45 \\
\hline & 4 & & 2 & Female & 40 \\
\hline & 5 & & 12 & Female & 78 \\
\hline & 6 & & 8 & Female & 72 \\
\hline \multirow{2}{*}{ Pandit[14] } & 1 & \multirow{2}{*}{56} & 24 & NS & NS \\
\hline & 2 & & 36 & NS & NS \\
\hline Schelfaut[15] & 1 & 20 & 4 & Male & NS \\
\hline Marson[16] & 1 & 35 & 26 & NS & NS \\
\hline Newman[17] & 1 & 81 & 46 & Male & 47 \\
\hline Fornell[18] & 1 & 49 & 15 & NS & NS \\
\hline \multirow{6}{*}{ Kennedy[20] } & 1 & \multirow{6}{*}{84} & 0.6 & Female & 39 \\
\hline & 2 & & 1.2 & Male & 76 \\
\hline & 3 & & 1.8 & Male & 78 \\
\hline & 4 & & 2.16 & Male & 74 \\
\hline & 5 & & 3.72 & Female & 84 \\
\hline & 6 & & 4.2 & Female & 69 \\
\hline
\end{tabular}




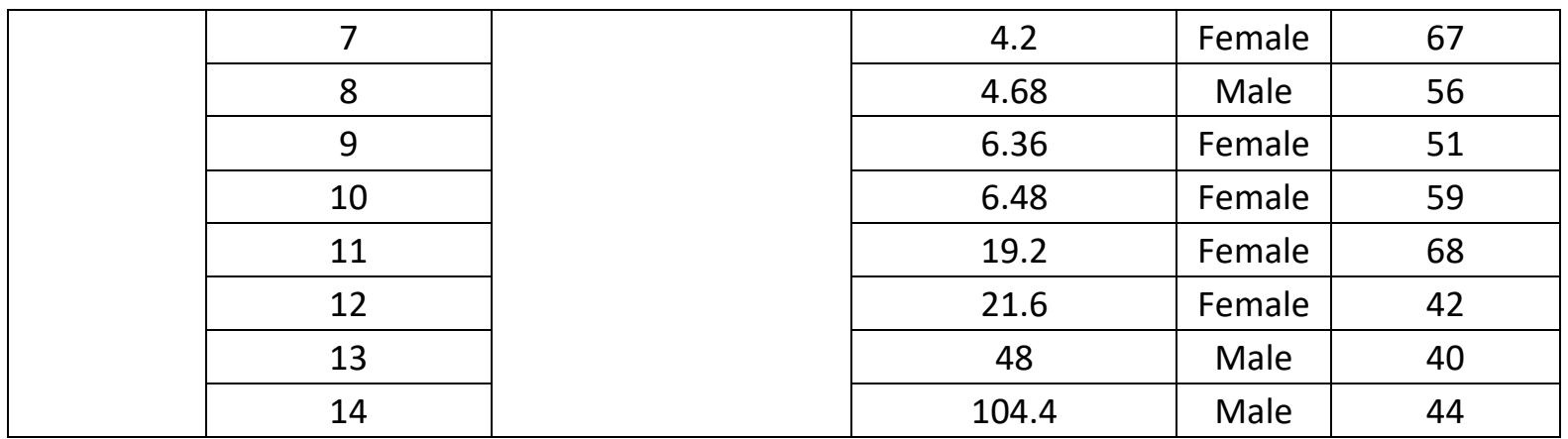

\subsection{Appendix B: Excluded studies}

Table B. 1. Excluded studies with reasoning after reading full manuscript.

\begin{tabular}{|c|c|c|c|}
\hline Author & $\begin{array}{l}\text { Publication } \\
\text { date }\end{array}$ & $\begin{array}{l}\text { Country of } \\
\text { study }\end{array}$ & Exclusion reason \\
\hline \multicolumn{4}{|c|}{ Flat tibial component } \\
\hline Goodfellow[33] & 1986 & UK & $\begin{array}{l}\text { Cannot separate out data of medial vs lateral } \\
\text { dislocations. }\end{array}$ \\
\hline Goodfellow[34] & 1987 & UK & $\begin{array}{l}\text { Not clear what information is lateral in this paper. } \\
\text { Additionally, uses same cohort as Goodfellow } \\
\text { (1988) paper. }\end{array}$ \\
\hline Goodfellow[29] & 1988 & UK & Bicompartmental series. \\
\hline Hangody[35] & 1992 & Hungary & $\begin{array}{l}\text { Information is not split out for the lateral Oxford } \\
\text { knee and it is a registry based study which was in } \\
\text { the exclusion criteria. }\end{array}$ \\
\hline Lewold[36] & 1995 & Sweden & Registry based study. \\
\hline \multicolumn{4}{|c|}{ Domed tibial component } \\
\hline Pandit & 2010 & UK & $\begin{array}{l}\text { The first series is a repeat of Gunther 1996, and } \\
\text { the third series is a repeat of Kennedy } 2020 \text {. }\end{array}$ \\
\hline Pandit[37] & 2012 & UK & $\begin{array}{l}\text { Repeat of the Gunther (1996) paper and Pandit } \\
\text { (2010) paper }\end{array}$ \\
\hline Streit[31] & 2012 & Germany & Repeat of the Walker (2018) paper. \\
\hline Altuntas[38] & 2013 & UK & Repeat of the Newman (2017) paper. \\
\hline $\begin{array}{l}\text { Weston- } \\
\text { Simons[27] }\end{array}$ & 2014 & UK & Repeat of Kennedy (2020) paper. \\
\hline Walker[39] & 2014 & Germany & No dislocation information. \\
\hline
\end{tabular}


Page $\mathbf{2 8}$ of $\mathbf{3 3}$

Masud[30]

2018

UK

Insufficient data regarding mean follow up period. 


\section{Page 29 of 33}

\subsection{Appendix C: MINORS risk assessment}

Table C. 1. Risk of bias assessment for included studies.

\begin{tabular}{|c|c|c|c|c|c|c|c|c|c|c|c|c|c|c|c|c|c|c|}
\hline Author & Year & $\begin{array}{c}\text { Countr } \\
y\end{array}$ & $\begin{array}{l}\text { Cle } \\
\text { arly } \\
\text { stat } \\
\text { ed } \\
\text { aim }\end{array}$ & $\begin{array}{c}\text { Inclusion } \\
\text { of } \\
\text { consecut } \\
\text { ive } \\
\text { patients }\end{array}$ & $\begin{array}{c}\text { Prospect } \\
\text { ive data } \\
\text { collectio } \\
\text { n }\end{array}$ & $\begin{array}{c}\text { Endpoint } \\
\text { s } \\
\text { appropri } \\
\text { ate to } \\
\text { study } \\
\text { aim }\end{array}$ & $\begin{array}{c}\text { Unbiase } \\
d \\
\text { assessm } \\
\text { ent of } \\
\text { study } \\
\text { endpoin } \\
t\end{array}$ & $\begin{array}{l}\text { Follow- } \\
\text { up } \\
\text { period } \\
\text { appropri } \\
\text { ate to } \\
\text { study } \\
\text { aim }\end{array}$ & $\begin{array}{c}<5 \% \\
\text { lost } \\
\text { to } \\
\text { follo } \\
\text { w up }\end{array}$ & $\begin{array}{l}\text { Prospect } \\
\text { ive } \\
\text { calculati } \\
\text { on of } \\
\text { study } \\
\text { size }\end{array}$ & $\begin{array}{l}\text { Adequ } \\
\text { ate } \\
\text { control } \\
\text { groups }\end{array}$ & $\begin{array}{l}\text { Contempor } \\
\text { ary groups }\end{array}$ & $\begin{array}{c}\text { Baseline } \\
\text { equivale } \\
\text { nce of } \\
\text { groups }\end{array}$ & $\begin{array}{c}\text { Adequ } \\
\text { ate } \\
\text { statisti } \\
\text { cal } \\
\text { analysi } \\
\text { s }\end{array}$ & $\begin{array}{c}\text { MINO } \\
\text { RS } \\
\text { score }\end{array}$ & $\begin{array}{c}\text { Samp } \\
\text { le } \\
\text { size }\end{array}$ & $\begin{array}{c}1^{\circ} \\
\text { outco } \\
\text { me } \\
\text { reporti } \\
\text { ng }\end{array}$ & $\begin{array}{c}\text { Ris } \\
k \\
\text { of } \\
\text { bia } \\
s\end{array}$ \\
\hline \multicolumn{19}{|c|}{ Flat tibial component } \\
\hline Kehr[13] & 1995 & France & 1 & 2 & 1 & 0 & 0 & 2 & 2 & 1 & N/A & N/A & N/A & N/A & 9 & C & A & $\mathrm{H}$ \\
\hline Gunther[1] & 1996 & UK & 0 & 2 & 1 & 0 & 1 & 2 & 2 & 0 & N/A & N/A & N/A & N/A & 8 & B & B & $\mathrm{H}$ \\
\hline Pandit[14] & 2010 & UK & 1 & 2 & 1 & 1 & 1 & 2 & 2 & 0 & N/A & N/A & N/A & N/A & 10 & B & B & $\mathrm{H}$ \\
\hline \multicolumn{19}{|c|}{ Domed tibial component } \\
\hline $\begin{array}{c}\text { Schelfaut[1 } \\
5]\end{array}$ & 2013 & $\begin{array}{c}\text { Belgiu } \\
\mathrm{m}\end{array}$ & 2 & 2 & 2 & 1 & 2 & 2 & 2 & 2 & N/A & N/A & N/A & N/A & 15 & c & A & $\mathrm{L}$ \\
\hline Marson[16] & 2014 & UK & 1 & 2 & 1 & 1 & 2 & 2 & 2 & 0 & N/A & $\mathrm{N} / \mathrm{A}$ & N/A & N/A & 11 & $\mathrm{C}$ & $B$ & $\mathrm{H}$ \\
\hline $\begin{array}{c}\text { Newman[17 } \\
]\end{array}$ & 2017 & UK & 2 & 2 & 2 & 2 & 2 & 2 & 2 & 1 & N/A & N/A & N/A & N/A & 15 & B & B & $\mathrm{L}$ \\
\hline Fornell[18] & 2018 & Spain & 2 & 2 & 1 & 2 & 2 & 2 & 2 & 0 & N/A & N/A & N/A & N/A & 13 & $\mathrm{C}$ & $B$ & $\mathrm{~L}$ \\
\hline Walker[19] & 2018 & $\begin{array}{c}\text { Germa } \\
\text { ny }\end{array}$ & 1 & 2 & 1 & 1 & 2 & 2 & 2 & 0 & $\mathrm{~N} / \mathrm{A}$ & $\mathrm{N} / \mathrm{A}$ & N/A & N/A & 11 & A & B & $\mathrm{H}$ \\
\hline $\begin{array}{c}\text { Kennedy[20 } \\
]\end{array}$ & 2020 & UK & 2 & 2 & 2 & 2 & 1 & 3 & 2 & 1 & $\mathrm{~N} / \mathrm{A}$ & $\mathrm{N} / \mathrm{A}$ & $\mathrm{N} / \mathrm{A}$ & $\mathrm{N} / \mathrm{A}$ & 15 & A & B & $\mathrm{L}$ \\
\hline
\end{tabular}


Page 30 of 33

\subsection{Appendix D: Search Strategy}

1. Arthroplasty, Replacement, Knee/

2. (partial knee or unicompartmental or unicondylar).ti,ab.

3. $\mathrm{OR} / 1-2$

4. partial.ti,ab.

5. unicompartmental.ti,ab.

6. unicondylar.ti,ab

7. uni.ti,ab.

8. (UKA or UKR or UCA or UCR or PKA or PKR or PCA).ti,ab.

9. meniscal.ti,ab

10. bearing.ti,ab.

11. dislocat*.ti,ab.

12. revis*.ti,ab.

13. re-operation.ti,ab.

14. reoperation.ti,ab.

15. surviv*.ti,ab.

16. Oxford.ti,ab.

17. failure.ti,ab.

18. mobile.ti,ab.

19. OR/4-18

20.3 AND 19

21. (robot* or total or TKA).m_titl.

22. 20 AND 21

23. (partial or unicompartmental or unicondylar or uni or UKA or UKR or UCA or UCR or PKA or PKR or PCA).m_titl. 
Page 31 of 33

\subsection{2 not 23}

25.20 not 24

Table D. 1. Summary of search outcomes.

\begin{tabular}{|c|c|c|}
\hline Database searched & Date searched & No. of outcomes \\
\hline $\begin{array}{l}\text { Medline (Ovid MEDLINE }{ }^{\circledR} \text { Epub } \\
\text { Ahead of Print, In-Process \& } \\
\text { Other Non-Indexed Citations, } \\
\text { Ovid MEDLINE }{ }^{\circledR} \text { Daily and Ovid } \\
\text { MEDLINE }^{\circledR} \text { ) } 1946 \text { to present }\end{array}$ & $15^{\text {th }}$ March 2019 & 4345 \\
\hline Embase 1974 to present & $15^{\text {th }}$ March 2019 & 3060 \\
\hline Manually added & $15^{\text {th }}$ March 2019 & 10 \\
\hline $\begin{array}{l}\text { Medline (Ovid MEDLINE }{ }^{\circledR} \text { Epub } \\
\text { Ahead of Print, In-Process \& } \\
\text { Other Non-Indexed Citations, } \\
\text { Ovid MEDLINE }{ }^{\circledR} \text { Daily and Ovid } \\
\text { MEDLINE }^{\circledR} \text { ) } 1946 \text { to present }\end{array}$ & $25^{\text {th }}$ May 2020 & 4927 \\
\hline Embase 1974 to present & $25^{\text {th }}$ May 2020 & 3421 \\
\hline ISI Web of Science & $22^{\text {nd }}$ June 2020 & 4941 \\
\hline
\end{tabular}

\subsection{Appendix E: Analysis of subgroups or subsets: deviations from PROSPERO}

Subgroup analyses were conducted to compare the effect estimate between studies to evaluate: Males versus female mobile bearing dislocation, geographic location of studies, and surgeon type (designer versus non-designer). Unfortunately, there was insufficient data to adequately assess the effect of geographical region and therefore, ethnicity and the impact of genetics. There was not a good spread of information regarding the geographical region, and most large studies published originated out of the designer surgeons based in the UK. Similarly, there was insufficient data to adequately assess the effect of surgeon caseload on mobile bearing dislocation. 


\section{References}

1. Gunther, T.V., et al., Lateral unicompartmental arthroplasty with the Oxford meniscal knee. The Knee, 1996. 3: p. 33-9.

2. Plancher, K.D., J.T. Alwine, and S.C. Petterson, Lateral unicondylar knee arthroplasty with lateral parapatellar incision returns athletes to moderate and vigorous sports: 2-11 year follow-up. Orthopaedic Journal of Sports Medicine, 2017. 5(7 Supplement 6).

3. van der List, J.P., et al., Patients with isolated lateral osteoarthritis: Unicompartmental or total knee arthroplasty? The Knee, 2016. 23(6): p. 968-974.

4. Ettinger, M., et al., In vitro kinematics of fixed versus mobile bearing in unicondylar knee arthroplasty. Archives of orthopaedic and trauma surgery, 2015. 135(6): p. 871-7.

5. Goodfellow J Fau-O'Connor, J. and J. O'Connor, The mechanics of the knee and prosthesis design. 1978(0301-620X (Print)).

6. O'Connor, J.J. and J.W. Goodfellow, Theory and practice of meniscal knee replacement: designing against wear. Proceedings of the Institution of Mechanical Engineers. Part $\mathrm{H}$, Journal of engineering in medicine, 1996. 210(3): p. 217-22.

7. Mohammad, H.R., et al., Long-term outcomes of over 8,000 medial Oxford Phase 3 Unicompartmental Knees-a systematic review. Acta orthopaedica, 2018. 89(1): p. 101-107.

8. Scott, R.D., Lateral unicompartmental replacement: a road less traveled. Orthopedics, 2005. 28(9): p. 983-4.

9. Bare, J.V., et al., A convex lateral tibial plateau for knee replacement. The Knee, 2006. 13(2): p. 122-6.

10. Campi, S., et al., Cementless fixation in medial unicompartmental knee arthroplasty: a systematic review. (1433-7347 (Electronic)).

11. de Vos-Kerkhof, E., et al., Tools for 'safety netting' in common paediatric illnesses: a systematic review in emergency care. (1468-2044 (Electronic)).

12. Slim, K., et al., Methodological index for non-randomized studies (minors): development and validation of a new instrument. (1445-1433 (Print)).

13. Kehr, P., et al., [The "Oxford" unicondylar knee prostesis (UCP): 21 reviewed cases]. La prothese unicompartimentale (PUC) "Oxford" A propos de 21 genoux revus., 1995. 5(3): p. 203-11.

14. Pandit, $\mathrm{H}$. ., et al., Mobile bearing dislocation in lateral unicompartmental knee replacement. The Knee, 2010. 17(6): p. 392-7.

15. Schelfaut, S., et al., The risk of bearing dislocation in lateral unicompartmental knee arthroplasty using a mobile biconcave design. Knee surgery, sports traumatology, arthroscopy : official journal of the ESSKA, 2013. 21(11): p. 2487-94.

16. Marson, B., et al., Lateral unicompartmental knee replacements: early results from a District General Hospital. European journal of orthopaedic surgery \& traumatology : orthopedie traumatologie, 2014. 24(6): p. 987-91.

17. Newman, S.D.S., et al., Up to 10 year follow-up of the Oxford Domed Lateral Partial Knee Replacement from an independent centre. The Knee, 2017. 24(6): p. 1414-1421.

18. Fornell, S., et al., Mid-term outcomes of mobile-bearing lateral unicompartmental knee arthroplasty. The Knee, 2018. 25(6): p. 1206-1213.

19. Walker, T., et al., Mid-term results of lateral unicondylar mobile bearing knee arthroplasty: a multicentre study of 363 cases. The bone \& joint journal, 2018. 100-B(1): p. 42-49.

20. Kennedy, J., et al., Oxford Domed Lateral Unicompartmental Knee Replacement: 10 year survival and 7 year clinical outcome. Bone and Joint Journal, 2020.

21. Borroff, M., et al., The NJR Editorial Board.

22. van Duren, B.H., et al., A new domed tibial lateral component provides improved range of movement \& retains normal kinematics for the Oxford UKR. Orthopaedic Proceedings, 2009. 91-B(SUPP_I): p. 47-48. 
23. Peersman, G., et al., Fixed-versus mobile-bearing UKA: a systematic review and meta-analysis. Knee surgery, sports traumatology, arthroscopy : official journal of the ESSKA, 2015. 23(11): p. 3296-305.

24. Pandit, $\mathrm{H}_{\text {., }}$ et al., The clinical outcome of minimally invasive Phase 3 Oxford unicompartmental knee arthroplasty: a 15-year follow-up of 1000 UKAs. The bone \& joint journal, 2015. 97-B(11): p. 1493-1500.

25. Deep, K., Collateral ligament laxity in knees: what is normal? Clinical orthopaedics and related research, 2014. 472(11): p. 3426-3431.

26. Tokuhara, Y., et al., The flexion gap in normal knees. An MRI study. 2004(0301-620X (Print)).

27. Weston-Simons, J.S., et al., The mid-term outcomes of the Oxford Domed Lateral unicompartmental knee replacement. The bone \& joint journal, 2014. 96-B(1): p. 59-64.

28. Verdonk, R., et al., The Oxford unicompartmental knee prosthesis: a 2-14 year follow-up. (0942-2056 (Print)).

29. Goodfellow, J.W., et al., The Oxford Knee for unicompartmental osteoarthritis. The first 103 cases. Journal of Bone and Joint Surgery - Series B, 1988. 70(5): p. 692-701.

30. Masud, S., et al., Oxford domed lateral unicompartmental knee arthroplasty: is it as good as Oxford medial unicompartmental knee arthroplasty? Orthopaedic Proceedings, 2017. 99B(SUPP_16): p. 19-19.

31. Streit, M.R., et al., Mobile-bearing lateral unicompartmental knee replacement with the Oxford domed tibial component: an independent series. The Journal of bone and joint surgery. British volume, 2012. 94(10): p. 1356-61.

32. Walker, T., et al., Minimally invasive lateral unicompartmental knee replacement: Early results from an independent center using the Oxford fixed lateral prosthesis. Knee, 2019.

33. Goodfellow, J.W. and J. O'Connor, Clinical results of the Oxford knee. Surface arthroplasty of the tibiofemoral joint with a meniscal bearing prosthesis. Clinical orthopaedics and related research, 1986(205): p. 21-42.

34. Goodfellow, J.W., et al., Unicompartmental Oxford Meniscal knee arthroplasty. The Journal of arthroplasty, 1987. 2(1): p. 1-9.

35. Hangody, L., et al., [Experience with the "Oxford" type uni-condylar meniscus-and surface replacing knee prosthesis. Preliminary report]. Az "Oxford" tipusu unicondylaris meniscus- es felszinpotlo terdprotezissel szerzett tapasztalataink. Elozetes jelentes., 1992. 35(3): p. 255-8.

36. Lewold, S., et al., Oxford meniscal bearing knee versus the Marmor knee in unicompartmental arthroplasty for arthrosis. A Swedish multicenter survival study. The Journal of arthroplasty, 1995. 10(6): p. 722-31.

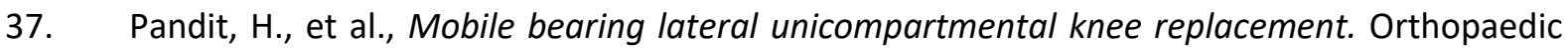
Proceedings, 2012. 94-B(SUPP_IX): p. 25-25.

38. Altuntas, A.O., H. Alsop, and J.P. Cobb, Early results of a domed tibia, mobile bearing lateral unicompartmental knee arthroplasty from an independent centre. The Knee, 2013. 20(6): p. 466-70.

39. Walker, T., et al., Total versus unicompartmental knee replacement for isolated lateral osteoarthritis: a matched-pairs study. International orthopaedics, 2014. 38(11): p. 2259-64. 